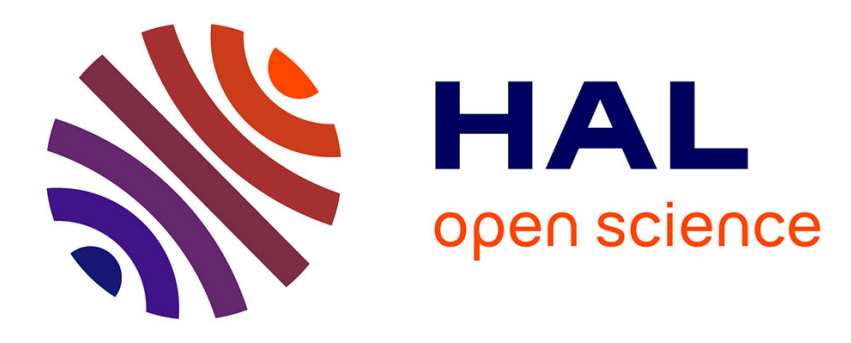

\title{
Unique silica polymorph obtained under electron irradiation
}

Imène Reghioua, Matthieu Lancry, Olivier Cavani, Sylvie Le Floch, Daniel R. Neuville, Nadège Ollier

\section{- To cite this version:}

Imène Reghioua, Matthieu Lancry, Olivier Cavani, Sylvie Le Floch, Daniel R. Neuville, et al.. Unique silica polymorph obtained under electron irradiation. Applied Physics Letters, 2019, 115 (25), pp.251101. 10.1063/1.5127836 . hal-02989616

\section{HAL Id: hal-02989616 https://hal.science/hal-02989616}

Submitted on 5 Nov 2020

HAL is a multi-disciplinary open access archive for the deposit and dissemination of scientific research documents, whether they are published or not. The documents may come from teaching and research institutions in France or abroad, or from public or private research centers.
L'archive ouverte pluridisciplinaire HAL, est destinée au dépôt et à la diffusion de documents scientifiques de niveau recherche, publiés ou non, émanant des établissements d'enseignement et de recherche français ou étrangers, des laboratoires publics ou privés. 


\title{
Unique silica polymorph obtained under electron irradiation
}

\author{
Cite as: Appl. Phys. Lett. 115, 251101 (2019); doi: 10.1063/1.5127836 \\ Submitted: 15 September 2019 • Accepted: 26 November 2019 . \\ Published Online: 16 December 2019
}

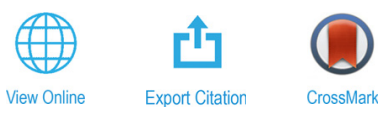

Imène Reghioua, ${ }^{1, a)}$ (D) Matthieu Lancry, ${ }^{2}$ Olivier Cavani, ${ }^{7}$ Sylvie Le Floch, ${ }^{3}$ Daniel R. Neuville, ${ }^{4}$ (D) and Nadège Ollier

\author{
AFFILIATIONS \\ 'Laboratoire des Solides Irradiés, CEA/DRF/IRAMIS, CNRS, Ecole Polytechnique, Institut Polytechnique de Paris, Route de Saclay, \\ 91128 Palaiseau, France \\ ${ }^{2}$ Institut de Chimie Moléculaire et des Matériaux d’Orsay, CNRS-Université Paris Sud, Université de Paris Saclay, \\ Bât.410, 91405 Orsay, France \\ ${ }^{3}$ Institut Lumière Matière, Univ Lyon, Université Claude Bernard Lyon1, CNRS, F-69622 Villeurbanne, France \\ ${ }^{4}$ Géomatériaux, CNRS-IPGP, Université de Paris, 1 rue Jussieu, 75005 Paris, France \\ a)imene.reghioua@polytechnique.edu
}

\begin{abstract}
High purity synthetic silica glass (Suprasil F300) samples were densified by High Pressure/High Temperature (HP-HT) using three different pressure/temperature/duration values. Their relaxation process was studied by applying $2.5 \mathrm{MeV}$ electron irradiation with doses varying from $1 \mathrm{MGy}$ up to $11 \mathrm{GGy}$. At very high dose (11 GGy), all the densified silica samples exhibit the same density value $\left(\sim 2.26 \mathrm{~g} / \mathrm{cm}^{3}\right)$ regardless of the densification conditions, referring to an equilibrium value known as an amorphous silica metamict phase. In detail, the HP-HT silica samples were progressively dedensified from 1 GGy irradiation dose until reaching this equilibrium. Whatever the initial topological disorder revealed through Raman spectra, all silica samples present identical Raman spectra at 11 GGy, with high intensities of $\mathrm{D}_{1}$ and $\mathrm{D}_{2}$ components, attesting they reach one unique silica polymorph. Regarding the irradiation at high temperature (600 MGy, $\left.600 \mathrm{~K}\right)$, the results show that the thermal annealing during irradiation "accelerates" somehow the relaxation kinetics of both macroscopic density and vibrational signature. Furthermore, it seems that such high irradiation temperatures lead to increase the Non-Bridging Oxygen Hole Center point defects generation.
\end{abstract}

Published under license by AIP Publishing. https://doi.org/10.1063/1.5127836

Nowadays, a high interest is given to the development of relevant technologies based on optics, photonics, and optoelectronics devices, thanks to their promising efficiency and vulnerability under severe conditions. One of the indispensable optical materials used in these technologies is the silica glass because of its numerous properties such as its ultratransparency in the UV-NIR spectral domain, high mechanical resistance, and low thermal expansion.

It is very important to fully understand the macroscopic and microscopic behavior of silica under the constraints of the intended applications, in order to ensure a long-term reliable operation of these devices in their environment. Indeed, a huge amount of research investigations has been dedicated to this material for tens of years, ${ }^{1-3}$ and yet some of its properties are still not well known.

From the microscopic point of view, silica glass is a simple amorphous material that is composed of a $3 \mathrm{D}$ continuous random network (CRN) of tetrahedron units; each unit consists of a silicon atom bounded to four oxygen atoms. ${ }^{1,4}$ These tetrahedra are arranged forming rings of different sizes. Their distribution ranges between 3 and 10 with a maximum of 6-membered rings. ${ }^{5}$ Several studies were held on the permanent densification of silica since 1950s after neutron irradiation. ${ }^{6}$ Density variation was investigated in vitreous silica, and its crystalline polymorph irradiated by different radiation types such as neutrons, ions, electrons, protons, UV laser, and IR femtosecond laser was also used in order to densify silica. ${ }^{6,7}$ The most widespread commercial application is the use of UV light that is employed to produce in-fiber/waveguide Bragg gratings by inducing refractive index change via two photon densification process and point defects creation. 8 The IR fs laser is also used to imprint a wide range of free space optical components as well as waveguides and Bragg gratings-based devices. $^{10}$

Under electron irradiation, some modifications are induced in the silica structure depending on the deposited dose. Raman spectroscopy is one of the most common techniques used to study the structural change in silica glass materials. In particular, in the case of 
densification by fs laser or electrons, the increase in the $\mathrm{D}_{2}$ Raman band area is well known and it corresponds to an increase in the 3membered rings associated with a decrease in the $\mathrm{Si}-\mathrm{O}-\mathrm{Si}$ average angle. ${ }^{11,12}$ On the other hand, the compaction of silica under high pressure (HP) has been more investigated. ${ }^{13}$ In detail, it has been demonstrated that under a pressure of $25 \mathrm{GPa}$ at room temperature, it is possible to reach a maximum densification degree of $\sim 21 \%(2.66 \mathrm{~g} /$ $\left.\mathrm{cm}^{3}\right) .{ }^{14}$ At higher temperature (HP-HT), the densification can be obtained with a lower pressure. ${ }^{13}$

The relaxation of hot compressed sample has been recently studied either following a thermal annealing by Cornet et al. ${ }^{15}$ and Guerette et al. ${ }^{16}$ or after irradiation. ${ }^{17}$ In particular, Guerette et al. aimed to characterize the High Density Amorphous (HDA) to Low Density Amorphous (LDA) transition in hot compressed silica samples. They showed that there is no thermal induced first order polymorphic transition like in amorphous ice, but they explained the multiplicity of configurational states in HDA silica with a funnelshaped rugged description of the energy landscape. Furthermore, in Ref. 18, we have shown that the relaxation of different densified silica samples under electron irradiation (up to a dose of $\sim$ GGy) seems to tend to a certain equilibrium value regardless of the initial densification stage and structure. Irradiation by fast neutrons causes a densification of vitreous silica ${ }^{19,20}$ that reaches a maximum value of $2.26 \mathrm{~g} / \mathrm{cm}^{3}$, i.e., an increase of approximately $3 \%$, after a dose of $10^{20}$ neutrons $/ \mathrm{cm}^{2}$. Quartz, tridymite, and cristobalite attain the same density after heavy neutron irradiation. The new phase is called amorphous metamict silica, a mineralogical term that describes the gradual and ultimately complete destruction of a crystal structure to yield an amorphous phase. On the other hand, a recent theoretical work made by ${ }^{17}$ showed the possibility to reproduce the experimental results of the density of $\alpha$-quartz irradiated up to $500 \times 10^{18}$ neutrons $/ \mathrm{cm}^{2}$. In particular, the calculations are in agreement with the density measurements up to $\sim 2.26 \mathrm{~g} / \mathrm{cm}^{3}$, and then the simulated density seems to decrease down to $2.2 \mathrm{~g} / \mathrm{cm}^{3}$.

The main purpose of this work is to improve the results obtained in Ref. 18 by irradiating new HP-HT densified samples with low electron irradiation doses $\left(10^{6}, 10^{7}\right.$, and $\left.10^{8} \mathrm{~Gy}\right)$ and $600 \mathrm{~K}$ irradiation $\left(6 \times 10^{8} \mathrm{~Gy}\right)$, but above all to check out the "equilibrium density value" at very high doses (11 GGy). To do so, we focused our attention on Raman spectroscopy for investigating the structural change and Photoluminescence (PL) for point defects generation.

Three different HP-HT conditions leading to three different densities (see Table I) were used to densify high purity synthetic silica glass known by Suprasil F300 ( $<1$ ppm of OH, typ. 2000 ppm of $\mathrm{Cl}$ ) from Heraeus. The densification was ensured by a belt press at Institut Lumière Matière (ILM) University of Lyon 1. The used method is well

TABLE I. Densification conditions of the tested samples. We remind that nontreated silica density is $2.2 \mathrm{~g} / \mathrm{cm}^{3}$.

\begin{tabular}{lccc}
\hline \hline Sample & Pressure & $T$ & Density \\
\hline $\mathrm{T}_{\mathrm{f}}-1250{ }^{\circ} \mathrm{C}$ & $\ldots$ & $\ldots$ & $2.206 \mathrm{~g} / \mathrm{cm}^{3}$ \\
$4 \mathrm{GPa} 4450^{\circ} \mathrm{C}$ & $4 \mathrm{GPa}$ & $450{ }^{\circ} \mathrm{C}$ & $2.294 \mathrm{~g} / \mathrm{cm}^{3}$ \\
$5 \mathrm{GPa} \_350^{\circ} \mathrm{C}$ & $5 \mathrm{GPa}$ & $350^{\circ} \mathrm{C}$ & $2.422 \mathrm{~g} / \mathrm{cm}^{3}$ \\
$5 \mathrm{GPa} \_1000^{\circ} \mathrm{C}$ & $5 \mathrm{GPa}$ & $1000^{\circ} \mathrm{C}$ & $2.612 \mathrm{~g} / \mathrm{cm}^{3}$ \\
\hline \hline
\end{tabular}

described in Ref. 21. The density measurements were held following the "sink-float method" which is based on the Archimedean technique. In detail, we measured the weights of the samples in the air and then in a known immersion liquid (toluene in our case). The density (in $\mathrm{g} / \mathrm{cm}^{3}$ ) of each sample can be deduced from the well-known relation between these weights, density, and the temperature of toluene $\left(\operatorname{density}(\mathrm{T})=0.8845-0.9159 \times 10^{-3} \times \mathrm{T}+0.368 \times 10^{-6} \times \mathrm{T}^{2}\right.$, $\mathrm{T}$ in $\left.{ }^{\circ} \mathrm{C}\right){ }^{22}$ The experiments were repeated 3 times, and the error is estimated to be less than $10^{-2}$. Both Raman spectroscopy and photoluminescence (PL) measurements were performed using an externally double diode laser emitting a continuum light at $488 \mathrm{~nm}$ from spectra physics, and a spectrometer of type SHAMROCK coupled to a CCD Andor camera is used for detection. We used SIRIUS electron accelerator facility in Laboratoire des Solides Irradiés for the irradiation of the densified samples, with an energy of $2.5 \mathrm{MeV}$, which ensures a homogenous irradiation along the samples' volume, and doses of $(1,10,100 \mathrm{MGy}$, and $11 \mathrm{GGy})$ at room temperature $(\mathrm{RT}=300 \mathrm{~K})$ and $600 \mathrm{~K}\left(6 \times 10^{8} \mathrm{~Gy}\right)$.

Density values' evolution under irradiation is shown in Fig. 1. We can notice that there are no big differences between the density of the HP-HT densified samples from 1 up to $100 \mathrm{MGy}$, and their values are comparable to the pristine ones. However, from approximately 1 GGy, these density values go down, ${ }^{18}$ and at very high doses (11 GGy), they seem to reach a unique value (around $2.26 \mathrm{~g} / \mathrm{cm}^{3}$ ) regardless of the densification conditions. We also underline that even the sample that was slightly densified by changing its fictive temperature $\left(\mathrm{T}_{\mathrm{f}}-1250^{\circ} \mathrm{C}\right)$ is reaching the same density at this very high dose.

Aiming to investigate the structural modifications, we performed Raman spectroscopy, and the obtained spectra of the different HP$\mathrm{HT}, \mathrm{T}_{\mathrm{f}}$ and nondensified F300 samples are shown in Fig. 2. In agreement with the literature, we can distinguish a difference in the spectral shapes of the densified pristine samples compared to the suprasil F300 reference sample [Fig. 2(a)]. In particular, there is a shift of the main band toward the lower frequencies indicating that the average angles of $\mathrm{Si}-\mathrm{O}-\mathrm{Si}$ have been reduced, in agreement with the respective density degree of the four densified samples. In addition, the FWHM of the $440 \mathrm{~cm}^{-1}$ band is decreasing, which also supports the density increase.



FIG. 1. Density measurements of the different tested samples from 1 MGy up to 11 GGy. 

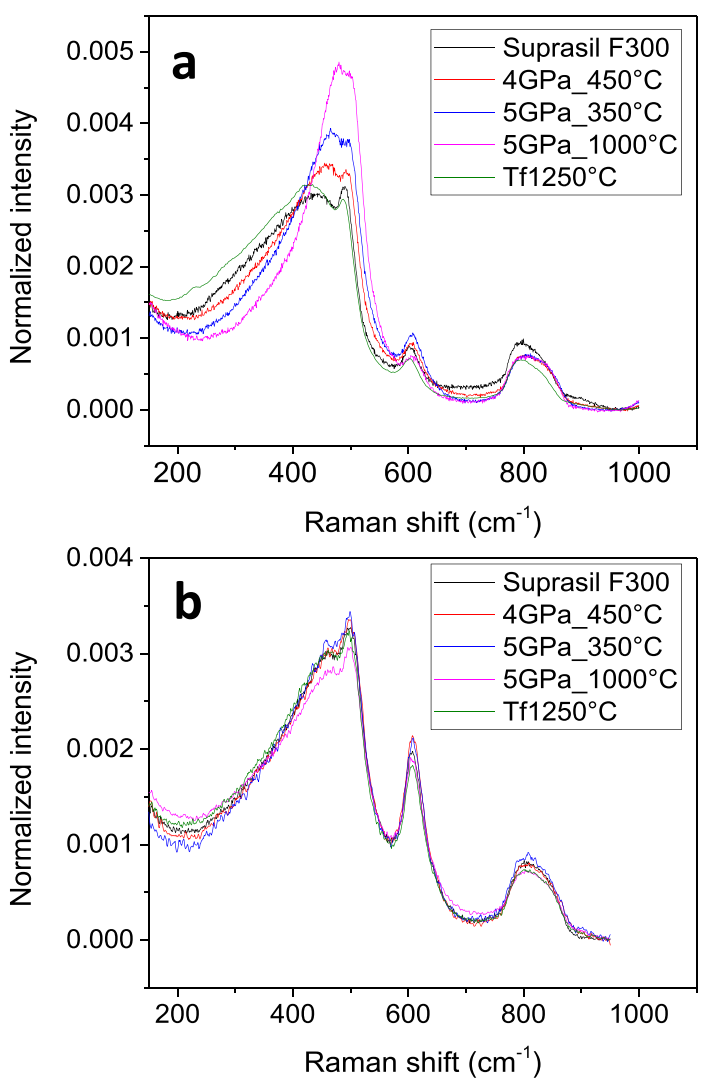

FIG. 2. Raman spectra of HP-HT and a reference Suprasil F300 nondensified sample: (a) Pristine samples. (b) Postmortem measurements after $11 \mathrm{GGy}$ of electron irradiation at room $\mathrm{T}$.

Furthermore, a variation of the $\mathrm{D}_{1}$ and $\mathrm{D}_{2}$ Raman bands intensities is noticed in the different spectra before irradiation.

When we irradiated these samples at RT and up to the dose of $100 \mathrm{MGy}$ by $2.5 \mathrm{MeV}$ electrons, we obtained no remarkable changes in terms of vibrational structure. Indeed, Raman spectra's shape of the irradiated samples from $1 \mathrm{MGy}$ up to $100 \mathrm{MGy}$ does not change compared to the ones of the pristine samples (data not reported here). These results are thus in agreement with the density stability displayed in Fig. 1.

Figure 2(b) illustrates the Raman spectra of all the HP-HT densified samples, the $\mathrm{T}_{\mathrm{f}}-1250^{\circ} \mathrm{C}$, and also the Suprasil F300 one that have been irradiated up to 11 GGy. Very similar Raman spectra are obtained regardless of the densification conditions, attesting for a relaxation of the network (namely, glass expansion for HP-HT samples but densification for the $\mathrm{T}_{\mathrm{f}}-1250^{\circ} \mathrm{C}$ sample) until getting a similar vibrational signature at $11 \mathrm{GGy}$, indicating the formation of a unique silica polymorph. These Raman spectra show a high intensity of the $\mathrm{D}_{2}$ band, which means the amount of 3-membered rings is quite high for this structural state compared to the nontreated silica. Here again, the increase in the $\mathrm{D}_{2}$ Raman band does not indicate a macroscopic densification of the related samples as already shown in Refs. 18 and 23.

This confirms our previous hypothesis reported in Ref. 18, where we expected that the macroscopic density of all silica glasses tends to reach a unique equilibrium $\left(2.26 \mathrm{~g} / \mathrm{cm}^{3}\right)$ value after irradiating at very high doses. In this contest, it is worth to mention that the thermally densified sample by changing its fictive temperature $\left(\mathrm{T}_{\mathrm{f}}=1250^{\circ} \mathrm{C}\right)$ shows also both the same Raman spectrum and density as the other HP-HT densified samples after 11 GGy irradiation. It seems that the silica network passes through different configurational disorder states with different rates depending on the densification conditions (amplitude, method, temperature) and the irradiation conditions until reaching an equilibrium state at $\sim 11 \mathrm{GGy}$, where both the vibrational signature and the macroscopic density are stable regardless of their densification history. It is worth reminding that after neutron irradiation, both alpha-quartz and silica ${ }^{19,20}$ show, in the same way, a density of around $2.26 \mathrm{~g} / \mathrm{cm}^{3}$.

In order to complete our investigations of the structural relaxation of the HP-HT densified silica glasses under electron irradiation, we performed a set of irradiations at $600 \mathrm{~K}$ with a dose of $600 \mathrm{MGy}$. Figure 3(a) compares Raman spectra of the $4 \mathrm{GPa} \_450^{\circ} \mathrm{C}$ densified sample irradiated at $600 \mathrm{MGy}$ at $300 \mathrm{~K}$ and at $600 \mathrm{~K}$. We can notice that there is a higher increase in the intensity of $D_{1}$ and $D_{2}$ Raman bands when the sample is irradiated at high temperature. Note we obtained the same tendency for the other HP-HT samples. At the same time, we remind from Fig. 2(b) that the intensity of the $\mathrm{D}_{2}$ band is very high in the $2.26 \mathrm{~g} / \mathrm{cm}^{3}$ silica phase. Also, the thermal relaxation


FIG. 3. Temperature effects on the $4 \mathrm{GPa} 450^{\circ} \mathrm{C}$ sample. (a) Raman spectra of irradiated samples at $600 \mathrm{MGy}$ at RT and $600 \mathrm{~K}$. (b) Photoluminescence spectra of the same samples excited at $488 \mathrm{~nm}$ and normalized to the intensity at $\sim 540 \mathrm{~nm}$. 
of densified silica has shown to induce an increase in the area of the $\mathrm{D}_{2}$ band during the transitory phase. ${ }^{15}$ This may indicate that at $600 \mathrm{~K}$ the relaxation process under irradiation is accelerated toward the equilibrium state revealing in such a way that the relaxation under irradiation is a thermally activated mechanism. Following this view, the density measurements of these samples irradiated at higher temperature show that their respective macroscopic densities (see Table II) are getting indeed closer to the $2.26 \mathrm{~g} / \mathrm{cm}^{3}$ value compared to the irradiated samples at RT.

Figure 3(b) illustrates the photoluminescence spectra excited at $488 \mathrm{~nm}$ of the same irradiated samples $\left(4 \mathrm{GPa} \_450^{\circ} \mathrm{C}\right)$ at RT and $600 \mathrm{~K}$. These spectra are normalized to the emission band at $\sim 545 \mathrm{~nm}$ (green luminescence). Our recent work ${ }^{24}$ has demonstrated a straight link between the green luminescence at $\sim 540 \mathrm{~nm}$ and the densification of silica. In particular, the defects responsible of this green luminescence are still unknown; however, it has been demonstrated that they are related to the silica densification. ${ }^{24}$ Also, it has been shown that the compaction of silica modifies the spectral shape of the emission of the Non-Bridging Oxygen Hole Center (NBOHCs) defects at $650 \mathrm{~nm}$, inducing an additional contribution at $\sim 610 \mathrm{~nm}$ interpreted as another NBOHC species with different surrounding environment. ${ }^{24}$

We can also distinguish here the contribution at $610 \mathrm{~nm}$ in the irradiated samples as shown in Ref. 24. Such finding is in agreement with results reported by Morana et al. ${ }^{25}$ where the authors highlighted some changes in the spectroscopic properties of the NBOHCs under neutrons irradiation. The interesting information here is the difference of ratio between the green and the $\mathrm{NBOHC}$ species luminescence as a function of the irradiation temperature. It seems that when the temperature is higher the ratio between these two emissions is higher compared to RT. This can be surprising if we considered that the high temperature "normally" leads to decrease the concentration of such defects (the NBOHCs are known to be annealed at $\mathrm{T} \sim 40{ }^{\circ} \mathrm{C}^{26}$ ).

However, in the case of "writing and erasure" processes that are thermally activated, it is expected to observe a faster kinetic as for $\mathrm{UV}$-induced refractive index changes in Ge-doped silica ${ }^{27}$ but also for many other distributed processes in glasse ${ }^{28}$ like radiodarkening, photodarkening, or the thermal relaxation of HP-HT silica. ${ }^{15}$ In this context, we can mention similar results that were presented by Girard et al. ${ }^{29}$ where the authors performed $\gamma$-rays irradiation up to $1 \mathrm{MGy}$ at $30{ }^{\circ} \mathrm{C}$ on pure-silica-core optical fibers, and they found out that the $\mathrm{NBOHC}$ 's concentration increases under these conditions. In our case, the higher amount of NBOHC may be also related to the greater creation of 4 and 3-membred rings at the expense of 6-membred rings at $600 \mathrm{~K}$. Further investigations are required in order to better explain the coupled irradiation-temperature effects in these samples.

In conclusion, several works ${ }^{6,7,14,15,17,20}$ have dealt with the structural modifications and density variation of compacted silica glass under HP, HP-HT, or different types of irradiation. The relaxation of these silica glasses with different topological disorder was also studied

TABLE II. Density measurements $\left(\mathrm{g} / \mathrm{cm}^{3}\right)$ of the tested samples at RT and at $600 \mathrm{~K}$.

\begin{tabular}{lccc}
\hline \hline Dose/T & $4 \mathrm{GPa} \_450{ }^{\circ} \mathrm{C}$ & $5 \mathrm{GPa} \_350^{\circ} \mathrm{C}$ & $5 \mathrm{GPa} \_1000^{\circ} \mathrm{C}$ \\
\hline $600 \mathrm{MGy}$ _300 K & 2.285 & 2.439 & 2.580 \\
$600 \mathrm{MGy}$ 600 K & 2.259 & 2.291 & 2.556 \\
\hline
\end{tabular}

under irradiation or thermal treatment. Depending on the initial compaction conditions, they exhibit different relaxation mechanisms following different physicochemical pathways. However, similarly to what is reported in silica polymorphs like quartz, tridymite, and cristobalite under neutrons irradiation, we demonstrate that at high dose electron irradiation (typ. 11 GGy), the density of all the studied samples reaches an equilibrium value around $2.26 \mathrm{~g} / \mathrm{cm}^{3}$, identical to the polymorphic silica metamict phase. In particular, whatever the initial topological disorder, all samples relax with different kinetics but they reach the same Raman signature "at equilibrium," describing a state mostly based on the associated 6-membered rings ${ }^{30}$ but with a high amount of 4 and 3 membered rings. This shares the view of the modulated structure model proposed by Marians and Burdett ${ }^{31}$ that consists of domains of ordered regions linked by interfacial less ordered regions. The ordered regions, while not crystalline, exhibit a tridymitelike structure, i.e., 6-ring local clusters, whereas interfacial regions contain larger as well as smaller rings.

The irradiation at $600 \mathrm{~K}$ accelerates the relaxation process emphasizing the role of $\mathrm{NBOHC}$ to reach this silica metamict state. This indicates that silica metamict phase formation is a thermally activated process. In addition, this reveals that silica relaxation under electron irradiation resembles the metamictization process observed in silica crystalline polymorphs and is likely related to the structural relaxation process of a highly "defective $\mathrm{SiO} 2$ matrix" triggered by a critical point defects concentration as suggested by Refs. 32 and 33. However, at this step, this is still unclear if there is a unique metamict phase, common to all silica polymorphs, provided they are irradiated with a sufficient high dose.

As a perspective, Rayleigh scattering seems to be a good experimental tool to provide further information about Rayleigh scattering in the different HP-HT densified samples before and after irradiation since such a technique is known to be sensitive to the refractive index and the density variation, and it can enrich the results reported in this paper.

The National Network EMIR was acknowledged for supporting the irradiation experiments in SIRIUS (No. 18-6129). The authors would like to thank l'Ecole Polytechnique for the junior postdoctoral grant. DEFI CNRS "Instrumentation aux Limites" was thanked for funding the Ultra-Bragg project.

\section{REFERENCES}

${ }^{1}$ Defects in $\mathrm{SiO}_{2}$ and Related Dielectrics: Science and Technology, edited by G. Pacchioni, L. Skuja, and D. L. Griscom (Springer Netherlands, Dordrecht, 2000).

${ }^{2}$ L. Skuja, J. Non-Cryst. Solids 239, 16 (1998).

${ }^{3}$ G. Pacchioni and G. Ierańo, Phys. Rev. B 57, 818 (1998).

${ }^{4}$ W. H. Zachariasen, J. Am. Chem. Soc. 54, 3841 (1932).

${ }^{5}$ W. Jin, R. K. Kalia, P. Vashishta, and J. P. Rino, Phys. Rev. B 50, 118 (1994).

${ }^{6}$ W. Primak, Phys. Rev. 110, 1240 (1958).

${ }^{7}$ R. A. B. Devine, Nucl. Instrum. Methods Phys. Res., Sect. B 91, 378 (1994).

${ }^{8}$ M. Lancry and B. Poumellec, Phys. Rep. 523, 207 (2013).

${ }^{9}$ N. F. Borrelli, C. Smith, D. C. Allan, and T. P. Seward, J. Opt. Soc. Am. B 14, 1606 (1997).

${ }^{10}$ B. W. McMillen, Y. Bellouard, O. Uteza, R. Clady, and M. Sentis, in CLEO QELSFundamental Science (Optical Society of America, 2016), p. JTh2A-34.

${ }^{11}$ B. Boizot, S. Agnello, B. Reynard, R. Boscaino, and G. Petite, J. Non-Cryst. Solids 325, 22 (2003).

${ }^{12}$ T. Gavenda, O. Gedeon, and K. Jurek, J. Non-Cryst. Solids 425, 61 (2015). 
${ }^{13}$ S. Kapoor, L. Wondraczek, and M. M. Smedskjaer, Front. Mater. 4, 1 (2017).

${ }^{14}$ T. Deschamps, A. Kassir-Bodon, C. Sonneville, J. Margueritat, C. Martinet, D. de Ligny, A. Mermet, and B. Champagnon, J. Phys.: Condens. Matter 25, 25402 (2013).

${ }^{15}$ A. Cornet, V. Martinez, D. de Ligny, B. Champagnon, and C. Martinet, J. Chem. Phys. 146, 94504 (2017).

${ }^{16}$ M. Guerette, M. R. Ackerson, J. Thomas, E. B. Watson, and L. Huang, J. Chem. Phys. 148, 194501 (2018).

${ }^{17}$ N. M. A. Krishnan, B. Wang, Y. L. Pape, G. Sant, and M. Bauchy, J. Chem. Phys. 146, 204502 (2017).

${ }^{18}$ N. Ollier, M. Lancry, C. Martinet, V. Martinez, S. Le Floch, and D. Neuville, Sci. Rep. 9, 1-8 (2019).

${ }^{19}$ A. Vanelstraete and C. Laermans, Phys. Rev. B 38, 6312 (1988).

${ }^{20}$ J. P. Bonnet, M. Boissier, and A. Ait Gherbi, J. Non-Cryst. Solids 167, 199 (1994).

${ }^{21}$ C. Martinet, A. Kassir-Bodon, T. Deschamps, A. Cornet, S. L. Floch, V. Martinez, and B. Champagnon, J. Phys.: Condens. Matter 27, 325401 (2015).

${ }^{22}$ D. R. Lide, CRC Handbook of Physics and Chemistry, 76th ed. (CRC Press, Boca Raton, USA, 2001).
${ }^{23}$ M. Heili, B. Poumellec, E. Burov, C. Gonnet, C. Le Losq, D. R. Neuville, and M. Lancry, J. Mater. Sci. 51, 1659 (2016).

${ }^{24}$ N. Ollier, K. Piven, C. Martinet, T. Billotte, V. Martinez, D. R. Neuville, and M. Lancry, J. Non-Cryst. Solids 476, 81 (2017).

${ }^{25}$ A. Morana, S. Girard, M. Cannas, E. Marin, C. Marcandella, P. Paillet, J. Périsse, J.-R. Macé, R. Boscaino, B. Nacir, A. Boukenter, and Y. Ouerdane, Opt. Mater. Express 5, 898 (2015).

${ }^{26}$ M. Will, S. Nolte, B. N. Chichkov, and A. Tünnermann, Appl. Opt. 41, 4360 (2002).

${ }^{27}$ B. Poumellec, J. Non-Cryst. Solids 239, 108 (1998).

${ }^{28}$ B. Poumellec and M. Lancry, Fibers 3, 206 (2015).

${ }^{29}$ S. Girard, C. Marcandella, A. Morana, J. Perisse, D. Di Francesca, P. Paillet, J.R. Mace, A. Boukenter, M. Leon, M. Gaillardin, N. Richard, M. Raine, S. Agnello, M. Cannas, and Y. Ouerdane, IEEE Trans. Nucl. Sci. 60, 4305 (2013).

${ }^{30}$ L. W. Hobbs, J. Non-Cryst. Solids 182, 27 (1995).

${ }^{31}$ C. S. Marians and J. K. Burdett, J. Non-Cryst. Solids 124(1), 1 (1990).

${ }^{32}$ M. Pascucci, J. Hutchison, and L. Hobbs, Radiat. Eff. 74, 219 (1983).

${ }^{33}$ L. Douillard and J.-P. Duraud, Nucl. Instrum. Methods Phys. Res., B 107, 212 (1996). 